\title{
Pathological vestibular symptoms presenting in a group of adults with HIV/AIDS in Johannesburg, South Africa
}

\author{
Katijah Khoza-Shangase ${ }^{a *}$ and Kayla Jade Van Rie ${ }^{a}$ \\ ${ }^{a}$ Department of Speech Pathology and Audiology, School of Human and Community Development, University of the Witwatersrand, Johannesburg, \\ South Africa \\ *Corresponding author, email: Katijah.Khoza@wits.ac.za
}

\begin{abstract}
Aim: The current study aimed to explore the pathological vestibular symptoms presenting in a group of adults with HIV/AIDS in Johannesburg, South Africa.

Design: A quantitative non-experimental research design was adopted where data was collected by means of a questionnaire with close-ended questions on 96 participants who were recruited from a teaching hospital's HIV/AIDS research unit.

Analysis: Data were analysed through descriptive statistics.

Results: Findings from the current study revealed that $17 \%$ of the sample studied presented with an occurrence of pathological vestibular symptoms. The most prominently reported pathological vestibular symptoms found were vertigo, dizziness, lightheadedness, unsteadiness and headaches. Of the participants experiencing vestibular symptoms, $69 \%$ reported experiencing co-occurring audiological symptoms. Collectively, these symptoms were found to have a significant effect on the participants' quality of life and their ability to work. Interestingly, however, current findings revealed that only $31 \%$ of the participants experiencing pathological vestibular symptoms had reported these symptoms to medical professionals.
\end{abstract}

Keywords: adults, HIV/AIDS, Johannesburg, pathological vestibular symptoms, quality of life, South Africa

\begin{abstract}
Introduction
In 2012, the South African National HIV Prevalence, Incidence and Behaviour Survey revealed that there were an estimated 6422179 people living with HIV in South Africa, making up $12.2 \%$ of South Africa's entire population. Statistics have revealed that South Africa has the highest rate of new HIV infections globally. ${ }^{1}$ The increasing incidence of HIV/AIDS as well as the increased life expectancy of the patients living with HIV/AIDS in South Africa due to the availability of antiretroviral (ARVs) treatments, calls for medical professionals to ensure that these patients maintain a good quality of life. ${ }^{1}$ Identifying the severity and nature of the vestibular manifestations in patients with HIV/ AIDS is of vital importance to the audiologist as vestibular symptoms can be debilitating, restrictive, dangerous, and may negatively affect the patient's quality of life. Thus, identification, appropriate referrals and management thereof is essential. ${ }^{2}$
\end{abstract}

Worldwide, a considerable amount of research has been done, exploring the audiological manifestations that are present in patients with HIV/AIDS. ${ }^{3}$ In South Africa, research done by Khoza has provided invaluable insight into the effects that ARVs and HIV/AIDS may inflict on the auditory system. ${ }^{4,5}$ There is, however, a paucity of published evidence about the impact that HIV/AIDS and ARV medications may have on the vestibular system, especially from South Africa. ${ }^{3}$ A review of the available literature suggests that patients with HIV/AIDS often present with disorders of the auditory and vestibular systems, however the severity and nature of the vestibular manifestations are still unknown. ${ }^{3}$

The effects that HIV/AIDS could have on the vestibular system can be divided into direct and indirect effects. The direct effects are the effects caused primarily by HIV itself. Indirect effects are the effects caused by opportunistic infections as the patient's immune system is ineffective in fighting off these infections. Alternatively, vestibulotoxic side effects from the medication that the patient has been prescribed (ARVs or medication taken to fight opportunistic infections) could also adversely affect the integrity of the vestibular system. ${ }^{6}$ Numerous studies have been conducted that reveal that the HIV-infected population is susceptible to acquiring hearing loss with the pathology at the level of the cochlea. ${ }^{4-6}$ It is important to realise that the vestibular system and the cochlea share a great deal of the same anatomy and physiology. Specifically, the membranous labyrinth and the endolymph are continuous from the cochlea to the vestibular system. Moreover, the nerve fibres transporting information from the cochlea and those carrying information from the vestibular system merge together to form the vestibulocochlear nerve. Understanding that the anatomy and physiology of the vestibular system and the cochlea are so closely connected, it seems logical and feasible that patients with HIV/AIDS may experience both audiological and vestibular pathological symptoms. ${ }^{3}$

Available evidence has shown that HIV/AIDS could in fact have a direct effect on the vestibular system. There is a paucity of published South African evidence exploring the effects of HIV/ AIDS on the vestibular system. One study conducted in Pretoria, South Africa, with a sample size of 53 HIV-positive adults and 38 HIV-negative adults revealed that HIV-positive individuals had a $61 \%$ higher risk of developing vestibular pathology than HIVnegative individuals. ${ }^{8}$ Khoza also identified that $9 \%$ of a sample size of 150 participants in her study reported that they had experienced vertigo. ${ }^{4}$

Internationally, more evidence has been published on the effects of HIV/AIDS on the vestibular system. An earlier study revealed that when patients with HIV/AIDS began presenting with pathological neurological signs and symptoms, many were also presenting with severe vestibular symptoms such as vertigo and vomiting. ${ }^{9}$ Results from another study which made use of objective vestibular assessment measures suggested that as patients progressed to the more severe stages of HIV/AIDS, 
the prevalence of vestibular pathologies, especially central vestibular pathologies, increased. . $^{10,11}$ A review summarising 13 peer-reviewed articles, however, revealed that both peripheral and central vestibular disorders could be identified in patients with HIV/AIDS irrespective of the stage of HIV/AIDS. ${ }^{3}$ Although the effect that the different stages of HIV have on the vestibular system is not certain, post-mortem studies have reported that HIV causes deterioration in the anatomy and physiology of the vestibular system. ${ }^{12}$ Indisputable evidence was revealed when particles, characteristic of the virus, were found in the central and the peripheral vestibular system. ${ }^{12}$

Complicating research into establishing a relationship between HIV/AIDS and the vestibular system are the indirect effects of HIV/AIDS on the vestibuar system. ${ }^{10}$ Two main common opportunistic infections found in the HIV/AIDS infected population appear to have a direct link with pathological vestibular symptoms; these are otosyphilis and tuberculosis (TB). A study revealed that patients infected with syphilis, especially syphilis meningitis, otosyphilis and neurosyphilis, present with vertigo and dizziness due to damage to the central or peripheral vestibular system. ${ }^{13}$ On the other hand, TB has been found to have a positive correlation with vestibular pathologies due to the indirect adverse effects of TB medication on the vestibular system. TB is diagnosed in $50 \%$ of patients with HIV/AIDS. ${ }^{14}$ Multiple national and international studies have specified that the medication (aminoglycosides) taken to manage TB is vestibulotoxic. ${ }^{15-17}$ Vestibulotoxicity is the ability of a specific medication to damage vestibular structures, such as the semicircular canals, the otolith organs (the saccule and the utricle), the vestibular aspect of the eighth cranial nerve and, lastly, the connections within the central nervous system. ${ }^{15}$

There has also been some controversy over whether or not antiretroviral therapy (ART) is vestibulotoxic. One study revealed that the highly active antiretroviral treatment (HAART) used to treat HIV/AIDS appeared to present no harmful association with vestibular functioning, and that it appeared to play a role in preventing vestibular damage. ${ }^{18}$ Another study concurred with these findings and concluded that there was no difference in vestibular functioning for participants receiving ARVs compared to those who were not. ${ }^{8}$ In contrast to these studies, another study suggested that there may be a negative relationship between ART and vestibular functioning. ${ }^{19}$ This Mexican study found that six out of 23 paediatric patients who were on HAART presented with asymmetries in caloric and rotatory testing during vestibular assessments. ${ }^{19}$ This conflicting evidence further emphasises the need for more research on the effects of ARVs on the vestibular system.

If ARVs were indeed found to be vestibulotoxic, it is reasonable that patients who are required to ingest both aminoglycosides and ARVs, could be at risk of compounding vestibulotoxic effects. This could result in serious damage to the vestibular system. The chemical composition of the aminoglycosides and ARVs have been found to react with the sensory neurons in the cochlea and vestibular system through a process of oxidation, subsequently causing permanent damage to the hair cells. ${ }^{20}$

Evidence suggests that there has been minimal documentation of pathological vestibular symptoms such as vertigo in patients with HIV. ${ }^{3}$ One reason why there are limited reports of pathological vestibular symptoms in this population is the fact that of all the medical pathologies and infections that these patients experience, the experience of vertigo or dizziness may possibly seem insignificant to them and, hence, not reported. ${ }^{3}$ The undervaluation of this symptom may be detrimental to the treatment plan, may have serious consequences on the patient's quality of life, and may have a negative impact on their social and vocational functioning. Another reason for this lack of documentation of vestibular symptoms in this population is that these symptoms can occur acutely and spontaneously recover; and, thus may not be reported to medical professionals. ${ }^{2}$ This highlights the importance of enquiry during case history interviews as undiagnosed vestibular symptoms do not only pose a danger for the affected individual, but have health and safety implications for the general public in which the affected individual functions, for example driving, and operating dangerous machinery and equipment.

It is important to note that dizziness and vertigo are not the same concept; patients with vertigo often describe the sensation of vertigo as 'dizziness', but less than half of those reporting dizziness have vertigo. ${ }^{21}$ Patients who present with vertigo often report that they get the false sensation or illusion of movement when there is in fact no movement. The illusionary movement is symptomatically rotatory in nature - patients often describing it as a spinning sensation. ${ }^{22} \mathrm{~A}$ German study revealed that patients presenting with vestibular symptoms commonly complained of a range of symptoms, such as vertigo, chronic dizziness, gait instability, headaches, oscillopsia and disequilibrium. ${ }^{23}$

Naturally, the occurrence of these pathological vestibular symptoms is distressing for the patient, particularly if the condition is chronic. ${ }^{2}$ Vertigo as well as its secondary symptoms are considerably debilitating for a patient. It affects their psychological state and ability to independently function and participate in everyday life, consequently affecting their quality of life..$^{2,3}$ Therefore, if patients with HIV/AIDS are susceptible to vestibular abnormalities, it is important that medical professionals are aware of this and manage these symptoms appropriately; hence, the importance of the current study which aimed to explore the pathological vestibular symptoms presenting in a group of adults with HIV/AIDS in Johannesburg, South Africa

\section{Materials and methods}

\section{Research aim}

The aim of this study was to explore the pathological vestibular symptoms presenting in a group of adults with HIV/AIDS in Johannesburg, South Africa.

\section{Secondary aims:}

A. To establish occurrence of pathological vestibular symptoms in this group.

B. To identify the most prominent pathological vestibular symptoms in this group.

C. To determine if vestibular symptoms co-occur with other audiological symptoms.

D. To describe if and how vertigo affects quality of life in this population.

E. To establish and describe management options for vestibular symptoms that participants in this sample have undergone. 


\section{Research design}

The research design was quantitative in nature. Quantitative research provides the researcher with objective data that is subject to minimal researcher bias. ${ }^{24}$ In addition to being quantitative in design, this study was also non-experimental in nature. A non-experimental design was selected because the aim was not to identify a causal relationship between variables. ${ }^{24,25}$

\section{Description of the participants}

\section{The sample}

The sample comprised a total of 96 participants, including both males and females. Participants were recruited from an HIV/AIDS clinic at an Academic Hospital in Johannesburg. Patients attending this clinic had already been diagnosed with HIV/AIDS and presented for general medical health monitoring and management.

\section{Sampling procedure}

A non-probability convenience sampling technique was utilised to recruit participants. ${ }^{26}$ Patients waiting in the queues for consultation with the doctor were approached and provided with an information letter describing the study. The researcher verbally explained the study and then provided the patients with time to read the information letter. Thereafter, the patients were asked if they would like to participate in the study.

\section{Participant selection criteria}

Because of the nature and treatment of HIV/AIDS and its opportunistic infections, it may be difficult to establish whether or not vestibular symptoms are due to the HIV/AIDS infection, the opportunistic infections or due to the medications taken. ${ }^{27}$ However, it is impossible to exclude the above-mentioned variables without excluding almost all of the HIV/AIDS infected patients in a study. ${ }^{4}$ Furthermore, when conducting research that is exploratory in nature, such variables cannot be excluded as the sample would not be a true representation of the population within the selected context. ${ }^{4}$ For these reasons the inclusion criteria were not overly restrictive. The research sample selection criteria included the following:

\section{- Participants between the ages of 18-55 years of age.}

This age group was selected because participants are no longer minors at the age of 18 , and are able to provide informed consent. Participants over the age of 55 were excluded in order to avoid misattribution of pathological vestibular symptoms to HIV/AIDS, opportunistic infections or to vestibulotoxicity when in actual fact they were due to aging of the vestibular system..$^{28}$

- Participants diagnosed with HIV/AIDS.

- Participants able to give informed consent to participate in the study. Thus, they needed to be alert and oriented to person, place and time during the study.

\section{Participant distribution}

The sample comprised 47 males and 49 females in order to compare the prevalence of pathological vestibular symptoms in males and females. There was an unequal distribution of participants across age groups or Centers for Disease Control and Prevention (CDC) stages. Distribution percentages are shown in Table 1.

\section{Testing protocol}

The researcher requested permission from all relevant authorities to conduct the study at the HIV/AIDS clinic; and, also applied for ethical clearance from the University's Medical Ethics
Table 1: Demographics of the participants $(N=96)$

\begin{tabular}{|c|c|c|c|c|c|}
\hline Factor & $\begin{array}{c}\text { Sub- } \\
\text { category }\end{array}$ & \multicolumn{3}{|c|}{ Number } & Percentage \\
\hline \multirow[t]{3}{*}{ Gender } & Male & \multicolumn{3}{|c|}{47} & $49 \%$ \\
\hline & Female & \multicolumn{3}{|c|}{49} & $51 \%$ \\
\hline & & $M$ & $\mathrm{~F}$ & Total & \\
\hline \multirow{3}{*}{$\begin{array}{l}\text { Age ranges } \\
\text { (years) }\end{array}$} & $18-30$ & 4 & 1 & 5 & $5 \%$ \\
\hline & $31-40$ & 19 & 25 & 44 & $46 \%$ \\
\hline & $41-55$ & 24 & 23 & 47 & $49 \%$ \\
\hline \multirow{6}{*}{$\begin{array}{l}\text { CD4 count (/ } \\
\left.\mathrm{mm}^{3}\right)(92 / 96 \\
\text { participants } \\
\text { had CD4 } \\
\text { counts) }\end{array}$} & $\begin{array}{l}\text { Asymptomat- } \\
\text { ic(stage 1) }\end{array}$ & & & & \\
\hline & $>500 / \mathrm{mm}^{3}$ & 2 & 16 & 18 & $20 \%$ \\
\hline & $\begin{array}{c}\text { Symptomatic } \\
\text { (stage 2) }\end{array}$ & & & & \\
\hline & $\begin{array}{c}200-499 / \\
\mathrm{mm}^{3}\end{array}$ & 35 & 27 & 62 & $67 \%$ \\
\hline & $\begin{array}{l}\text { AIDS (stage } \\
3 \text { ) }\end{array}$ & & & & \\
\hline & $<200 / \mathrm{mm}^{3}$ & 7 & 5 & 12 & $13 \%$ \\
\hline \multirow[t]{2}{*}{ Vertigo } & Present & 6 & 10 & 16 & $17 \%$ \\
\hline & Absent & 41 & 39 & 80 & $83 \%$ \\
\hline \multirow{2}{*}{$\begin{array}{l}\text { Hearing } \\
\text { status }\end{array}$} & Present & 9 & 12 & 21 & $22 \%$ \\
\hline & Absent & 38 & 37 & 75 & $78 \%$ \\
\hline \multirow[t]{2}{*}{ Tinnitus } & Present & 14 & 17 & 31 & $32 \%$ \\
\hline & Absent & 33 & 32 & 65 & $68 \%$ \\
\hline \multirow{2}{*}{$\begin{array}{l}\text { Aural full- } \\
\text { ness }\end{array}$} & Present & 8 & 17 & 25 & $26 \%$ \\
\hline & Absent & 39 & 32 & 71 & $77 \%$ \\
\hline \multirow[t]{2}{*}{ Otalgia } & Present & 6 & 3 & 9 & $9 \%$ \\
\hline & Absent & 41 & 46 & 87 & $91 \%$ \\
\hline \multirow[t]{2}{*}{ Otorrhea } & Present & 2 & 1 & 3 & $3 \%$ \\
\hline & Absent & 45 & 48 & 93 & $97 \%$ \\
\hline
\end{tabular}

Committee. Once permission was obtained and ethical clearance secured interviews were conducted, with willing participants and patient records on the electronic database were reviewed. All data were collated on an Excel spreadsheet for convenient data handling.

The researcher conducted an interview with each participant where they were required to answer questions quantitatively (predominantly yes/no questions). Next, all participants electronic files were reviewed and the following information was extracted:

- The participant's medical and ear-related history/complaints.

- The participant's most recent CD4 count and viral load results.

- The participant's current medication and the length of time the patient had been taking this medication.

Medical file review was critical for the current study in order to determine the numbers of reported cases versus unreported but positive vestibular cases; as well as to glean all medical variables that would aid in appropriate data interpretation.

\section{Material}

For the purposes of this study, a questionnaire was used (Appendix A). This questionnaire combined questions from the 


\section{DISTRIBUTION}
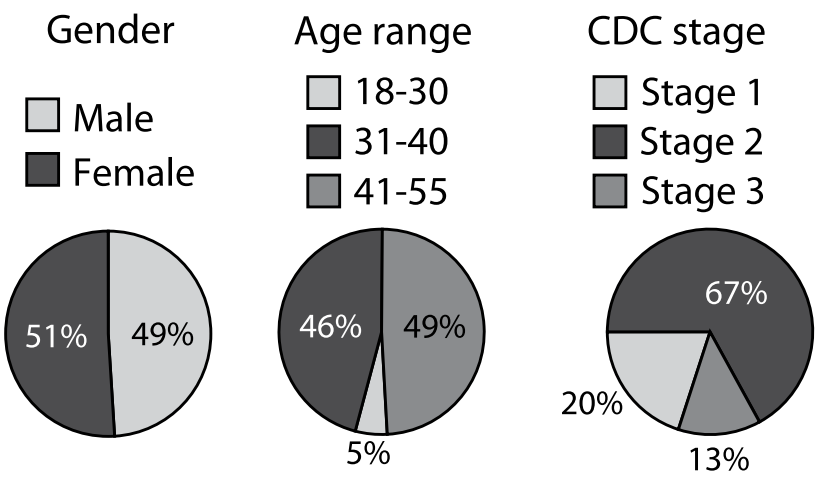

Figure 1: Participant distribution.

case history form used in Khoza's study, ${ }^{4}$ a vestibular clinic case history form used by the vestibular disorders association, ${ }^{29}$ as well as questions from the Dizziness Handicap Inventory. ${ }^{30}$ An interview was conducted instead of self-completion of the questionnaires. This was done to overcome anticipated varied levels of literacy as well as proficiencies in English. Furthermore, the chosen method allowed participants an opportunity to expand on answers, which they might not otherwise done in a self-completed questionnaire. ${ }^{31}$

\section{Analysis of data and statistical procedures}

The data obtained was analysed using descriptive statistics. The researcher analysed the data in order to establish and identify the answers to the 5 sub-aims of this study.

\section{Reliability and validity}

A pilot study to assess the reliability and validity of the research tool as well as study design was conducted prior to the main study. All necessary changes were made to the research tool and design following pilot study analysis, but prior to the main study. Data collection was kept consistent between participants; and analysis included independent rating of at least $50 \%$ of the data.

\section{Results and discussion}

\section{Description of the sample versus the population}

Although, the current sample was not representative of the gender distribution of HIV/AIDS population as it had more males than females (the population statistics of those infected with HIV/AIDS is reported to be $9.9 \%$ males and $14.4 \%$ females $^{1}$ ); the age range and $\mathrm{CDC}$ stage distribution (Figure 1) were representative. ${ }^{1,32}$

\section{The occurrence of vertigo}

The symptoms experienced by a person with a vestibular pathology may be multifarious. Many of these symptoms are common to both vestibular disorders and a multitude of other pathologies not involving the vestibular system, for example dizziness, unsteadiness, visual changes, headaches, nausea and vomiting. ${ }^{33}$ However, the symptom of vertigo has been identified as a symptom that is usually indicative of a vestibular disorder, ${ }^{34}$ thus a positive report of vertigo was required for the participant to be declared as part of the sample percentage representing participants with possible vestibular pathologies.

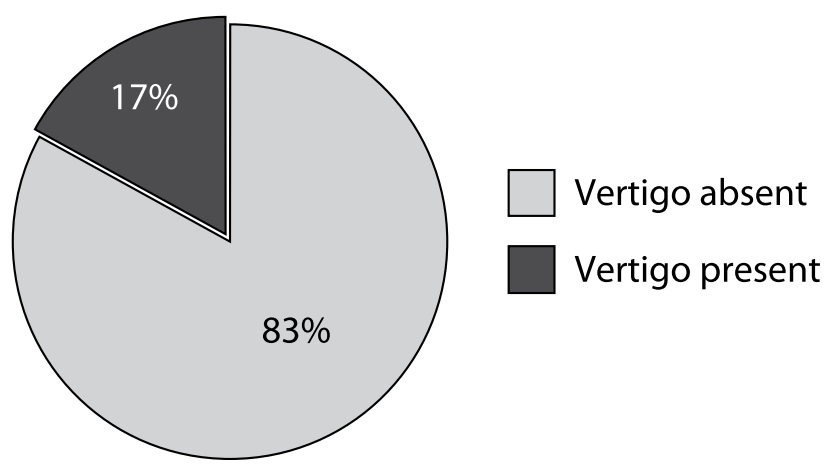

Figure 2: The occurrence of vertigo in the sample evaluated $(N=96)$.

Of the total sample of 96 participants, 16 (17\%) had experienced vertigo before, as depicted in Figure 2.

This finding was consistent with the literature that suggests that there is a prevalence of pathological vestibular symptoms within the population of HIV/AIDS infected individuals; with evidence from South Africa indicating that patients with HIV/AIDS have a higher risk of developing a vestibular pathology than HIV negative individuals. ${ }^{8}$ Causal factors including primary HIV/AIDS causes, and opportunistic infections were found to possibly affect the vestibular system, ${ }^{3}$ both centrally and peripherally. ${ }^{12}$

Interestingly, current findings revealed a greater occurrence of vertigo reports than what Khoza ${ }^{4}$ had found in her previous study, where only $9 \%$ of the sample presented with vertigo. This could be due to the fact that the current study was specific to vestibular function, thus had a more focused research tool. Khoza's study ${ }^{4}$ focused on identifying hearing loss in patients with HIV/AIDS, whereas this current study was focused on identifying vestibular symptoms in patients with HIV/AIDS, and thus the tool adopted for this current study may have been more sensitive and more specific than that used in Khoza's study. ${ }^{4}$ Furthermore, the extensive ARV treatment roll-out in South Africa post-2004 may have an influence on current findings. The treatment regime by HAART was rolled out to state patients in South Africa in 2004..$^{32,35}$

\section{HAART and vestibulotoxicity}

Current findings revealed that of the 16 participants experiencing vertigo, 10 reported the onset of the vertigo to be associated with the beginning of a specific course of treatment: eight of these participants were prescribed Atroiza ${ }^{\circ}$, and two were prescribed Aluvia. This finding suggests that what the ARV patients were receiving could have an effect on their vestibular function. Atroiza ${ }^{\circ}$ and Aluvia appeared to be commonly prescribed ARVs at the clinic, with $71 \%$ of the total sample taking Atroiza $^{\circ}$ and $15 \%$ taking Aluvia.

Current findings seem to contradict findings of Cohen et al. ${ }^{18}$ and Heinze et al., ${ }^{8}$ who reported that HAART appeared to have no harmful effect on vestibular functioning. Current results, however, are consistent with findings from a study on paediatric HIV/AIDS, which found that children and adolescents on HAART presented with vestibular abnormalities. ${ }^{19}$

No published evidence linking Atroiza $^{\circ}$ and Aluvia to vestibulotoxicity could be found. Thus, further studies with objective vestibular measures are necessary to test current findings. 
Table 2: Frequency of co-occurring audiological symptoms

\begin{tabular}{|l|c|}
\hline $\begin{array}{l}\text { Co-occurring audiological symptom } \\
\text { (with vertigo) }\end{array}$ & Number of occurrences \\
\hline Tinnitus & $9 / 11(81 \%)$ \\
\hline Aural fullness & $8 / 11(72 \%)$ \\
\hline Hearing loss & $5 / 11(45 \%)$ \\
\hline Otalgia & $3 / 11(27 \%)$ \\
\hline Otorrhea & $2 / 11(18 \%)$ \\
\hline
\end{tabular}

\section{Occurrence in males versus females}

Of the participants experiencing vertigo in the current study, a large majority (62\%) were female. This is contrary to reports by Cohen et $a .{ }^{18}$, whose study found that there was no relationship between gender and the occurrence of vertigo in the HIV/AIDS population. Current findings seem to indicate a greater preponderance for vestibular disturbances in females with HIV/ AIDS than in males. However, current findings are consistent with the general HIV-negative population, where women are reported to be more susceptible to vertigo than men. ${ }^{36}$

\section{Co-occurrence of audiological symptoms}

Overall, 11/16 (69\%) of the participants reported experiencing co-occurring audiological symptoms with the vertigo they had experienced. All of these participants (11) reported multiple audiological symptoms. This finding raised a strong index of suspicion for the experienced vertigo to be ear related. The number of times participants reported various audiological symptoms co-occurring with vertigo is displayed below (Table 2):

Tinnitus appeared to be the most commonly co-occurring symptom. It is possible that the tinnitus present in the sample may have been caused by a pathology that is not ear-related; however, taking into account that tinnitus is most commonly indicative of a sensorineural hearing loss, the presence of tinnitus may be strongly indicative of this. ${ }^{37}$ If this were the case, the presence of the tinnitus could be suggestive of decreased hearing sensitivity, however the reports of a subjective hearing loss were less than that of tinnitus in the current sample. This may be due to the fact that hearing sensitivity in these patients may have decreased, but not sufficiently for them to have noticed a hearing loss subjectively; particularly if the hearing loss was a high frequency hearing loss commonly reported in this population.

Interestingly, 16 (22\%) of the participants in the entire sample reported that they felt that their hearing sensitivity had diminished. Of these 16 participants, 5 reported that they had also experienced vertigo. This is supported by available literature in which more reports of auditory than vestibular manifestations were identified in patients with HIV/AIDS. ${ }^{3}$

Patients with HIV/AIDS are prone to middle ear infections and, thus, conductive hearing loss; however, only three participants in the current study complained of experiencing otalgia and otorrhea, which are symptoms indicative of a middle ear pathology. Another study also identified a much larger prevalence of sensorineural hearing losses than conductive hearing losses within the South African HIV/AIDS population. ${ }^{4}$

\section{Prominent pathological vestibular symptoms}

Along with the report of vertigo, participants reported experiencing other debilitating pathological vestibular symptoms. The results are displayed in Figure 3.

The results revealed that the most commonly occurring pathological vestibular symptoms were: vertigo, dizziness, lightheadedness, unsteadiness, headaches, visual changes, nausea and vomiting. Research on vestibular abnormalities commonly discuss the symptoms of dizziness and vertigo; however, very little information appeared to be available with regard to other secondary physical and psychological symptoms the patient may have experienced. The results depicted in Figure 3 revealed that the participants'symptoms were multifarious and require attention during clinical assessment and management of this population.

The scope of the current study did not allow for a clear determination of whether these symptoms were indicative of central or peripheral vestibular pathology as further objective testing would need to be conducted to confirm this; an implication for further research. Many of the presenting symptoms found in the current study are identifiable in both central and peripheral pathologies; however, the presence of headaches and confusion is more common in central pathologies, while the presence of nausea and vomiting is more common in

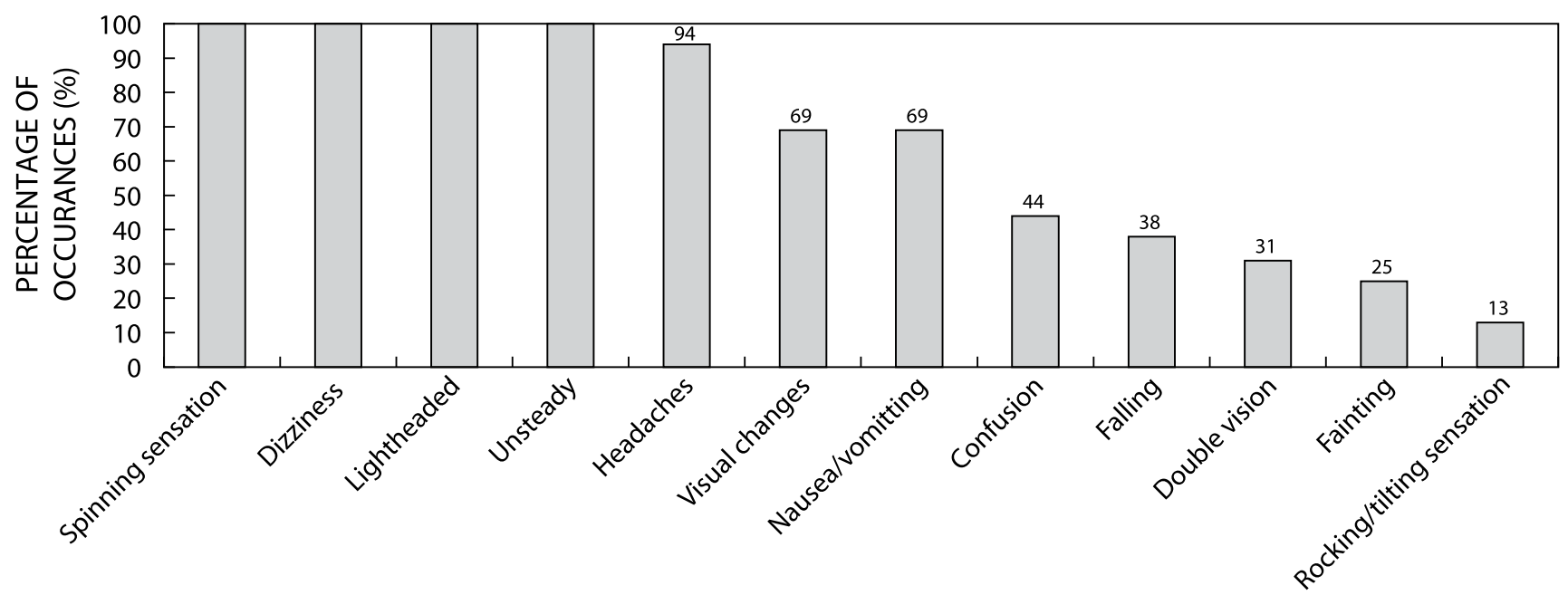

VESTIBULAR SYMPTOMS

Figure 3: The occurrence of pathological vestibular symptoms $(N=16)$. 


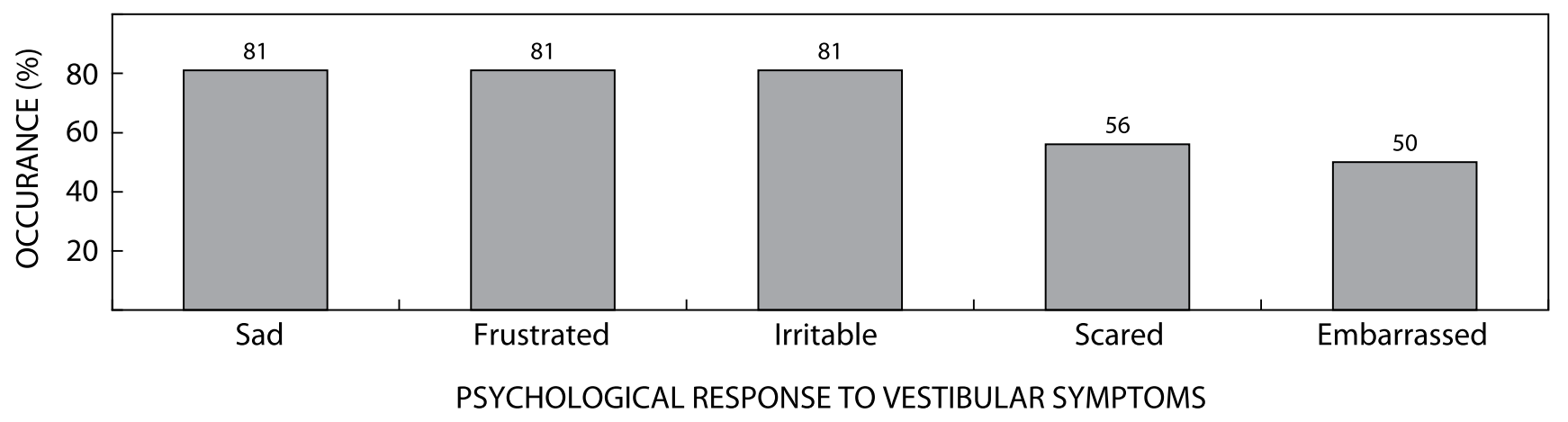

Figure 4: The psychological effect that vestibular symptoms had on participants experiencing vestibular symptoms $(N=16)$.

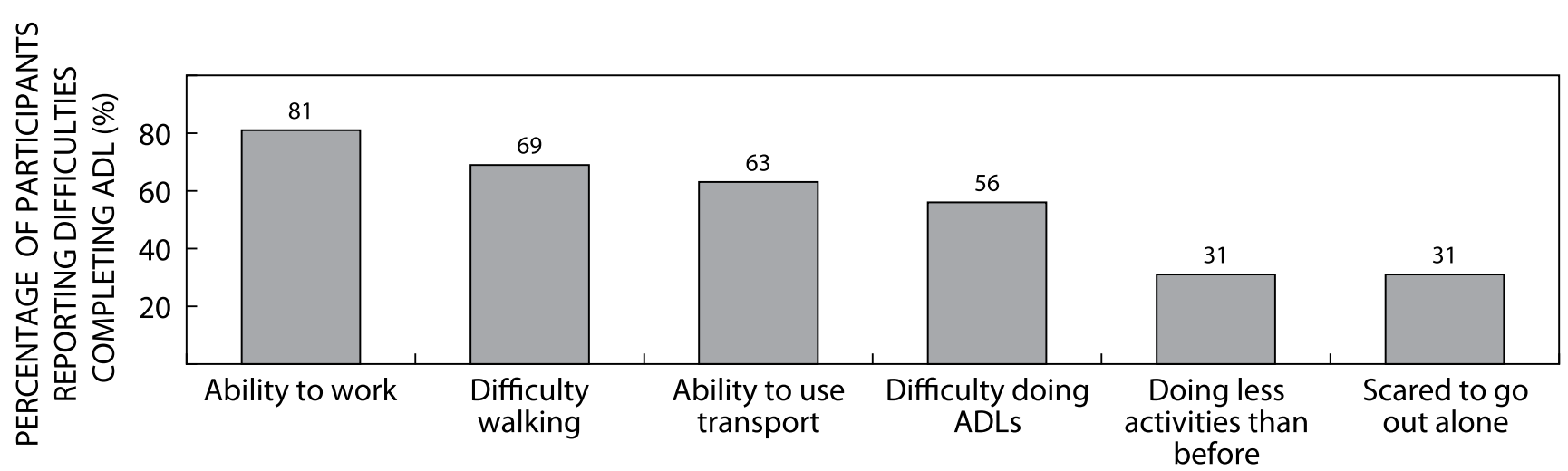

ACTIVITIES OF DAILY LIVING

Figure 5: The effect that the pathological vestibular symptoms had on the participants' activity and participation in everyday life $(N=16)$.

peripheral pathologies. ${ }^{37}$ This suggests that both central and peripheral vestibular pathologies might have been prevalent in the current sample. The fact that the HIV/AIDS population presents with medically complex symptomatology makes the causal links difficult to establish, thus these symptoms could be indicative of pathology non-related to the vestibular system.

\section{The effect of vertigo on quality of life in HIV/AIDS infected adults}

Research has revealed that vertigo as well as its secondary symptoms are considerably debilitating for a patient. It affects their ability to function and participate in everyday life, affecting their quality of life, with serious implications for the health and safety of the affected individual and those around him/her., ${ }^{2,3}$

\section{Psychological symptoms}

Current findings, as depicted in Figure 4, revealed that the most commonly reported psychological effects that patients with HIV/ AIDS who had experienced vertigo were: sadness, frustration and irritability. Interestingly, there were fewer reports of feelings offear and embarrassment, which appears to be the psychological symptoms that are more commonly reported in the literature. ${ }^{38-40}$

Current findings suggest that pathological vestibular symptoms in the HIV/AIDS population elicit feelings that could contribute to depression. Reports indicate that there is a high prevalence of patients with HIV/AIDS who experience depression due to the constant burden of having to live with HIV/AIDS, and endure the resultant pathological medical symptoms, the stigma and discrimination that occurs with having been diagnosed with HIV/AIDS - all contribute to the development of depression in this population..$^{41}$ Healthcare workers need to be aware that if patients are experiencing pathological vestibular symptoms, especially persistent symptoms, they may be more likely to develop depression, and thus management thereof is imperative.

\section{Activities of daily living}

Literature has documented how pathological vestibular symptoms prohibit patients from taking part in some functional, leisurely and social activities. ${ }^{2}$ Participants were asked to identify if the pathological vestibular symptoms were of the significant symptoms that played a role in disabling them with regard to daily activities and participation. The results are displayed in Figure 5:

A large majority of participants (81\%) reported that the pathological vestibular symptoms affected their ability to work. At least half of participants experiencing vestibular symptoms reported that they were unable to perform effectively and efficiently in their occupations. ${ }^{42}$ The argument advanced is that it appeared as though the vestibular symptoms, alongside a multitude of medical symptoms experienced by the participants, may have had a compounding effect, leaving patients feeling debilitated and unable to complete tasks that may have been previously done with ease. ${ }^{42}$ Another study also recognised that many patients who experienced vestibular symptoms had to learn to adapt their lifestyles. ${ }^{43}$ Furthermore, the fear of going out alone has been reported as one of the main contributing factors to a poorer quality of life for patients experiencing pathological vestibular symptoms. ${ }^{2}$

Although $56 \%$ of the participants reported that they had felt anxious due to the vertigo, only $31 \%$ of the participants reported feeling afraid to going out alone. One participant stated: "If I am scared to go out how can I make money to feed my family?" Perhaps this statement is a reflection of the socio-economic reality that many South Africans live with, where debilitating 
symptoms are set aside as they act as an inconvenience to basic survival. Many family units in South Africa are reliant on one guardian/family member to provide an income for the rest of the family as parents have passed away due to HIV/AIDS.44

Participants also reported having difficulty walking, difficulty using transport and also reported doing fewer activities than previously done due to the vertigo. This reality makes patients feel socially isolated and alone. ${ }^{2}$ In this population, however, it appears that these factors add to feelings of sadness. This should be one of the priorities for healthcare professionals, as one of the goals of ARV treatment in South Africa is to ensure that patients living with HIV/AIDS are experiencing the best possible quality of life. ${ }^{14}$ These findings imply that patients with HIV/AIDS may be experiencing a poorer quality of life due to unidentified, untreated or unmanaged vestibular symptoms.

\section{Management options for vestibular symptoms which adults with HIV/AIDS have undergone}

In the current study, as depicted in Figure 6,69\% of the participants (who were experiencing pathological vestibular symptoms) did not report the symptoms to the attending healthcare workers. In light of all the medical pathologies and infections these patients are experiencing, the fact that they are experiencing vertigo or dizziness may have seemed insignificant to them, hence they did not report their symptoms for assessment and management. Some of the participants reported that the vestibular symptoms occurred acutely and spontaneously recovered and, for this reason, were not reported to medical professionals.

As depicted in Figure 6, of the participants with vertigo, 31\% stated that they had mentioned to the medical professionals that they were experiencing vestibular symptoms. Many of these participants reported that the doctors had told them that their symptoms were due to their medication and that experiencing these symptoms was a reality that they may need to get used to. Some participants also reported that the doctor prescribed medication to address these symptoms. None of the participants, even those experiencing pathological vestibular symptoms regularly, were referred for any vestibular assessment and/or rehabilitation.

When analysing why patients were not being referred for vestibular rehabilitation, the South African healthcare context needed to be acknowledged. In South Africa, patients speak many different languages and are often required to communicate to medical professionals through an interpreter or in a language that is not their home language. In the patient's indigenous

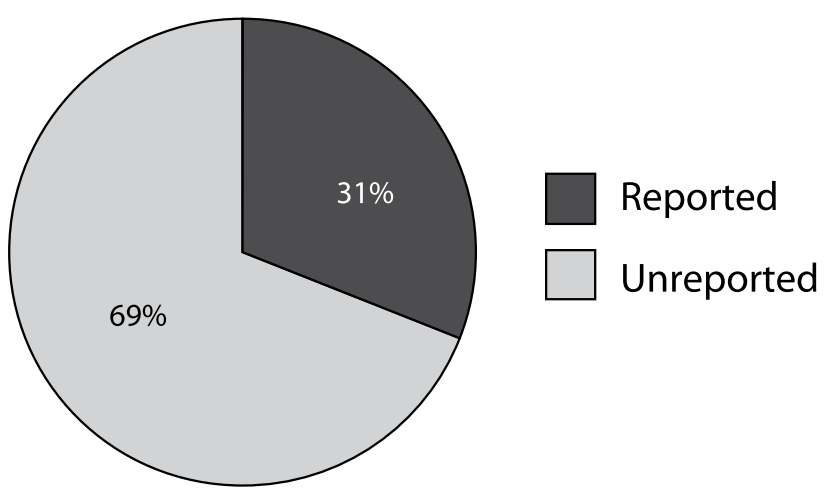

Figure 6: Number of participants who reported the pathological vestibular symptoms to healthcare workers versus the number of participants who did not $(N=16)$. language, there may not be specific words that describe their vestibular symptoms adequately and, if the patient is speaking a second language, the patient's vocabulary may insufficiently describe their symptoms. ${ }^{15}$ Patients may also use various terms for vestibular symptoms, such as 'dizzy', 'weak' and 'sick' to 'giddy' and 'spinning'. The descriptions patients often offer can be attributed to various pathologies or medications and, thus, may not alert doctors to the possibility of vestibular dysfunction. ${ }^{15}$ Furthermore, lack of adequate and sufficient vestibular assessment as well as rehabilitation specialists who have appropriate objective equipment might be an influencing factor.

\section{Conclusion}

In summary, findings from the current study revealed that there was an occurrence of pathological vestibular symptoms in $17 \%$ of the sample studied, higher in women than in men. The most prominent pathological vestibular symptoms in this sample were vertigo, dizziness, light-headedness, unsteadiness and headaches. Sixty-nine percent $(69 \%)$ of the participants experiencing vestibular symptoms also reported experiencing co-occurring audiological symptoms, with the most common to the least common symptoms being: tinnitus, aural fullness, hearing loss, otalgia, and otorrhea. Understandably, these symptoms were found to significantly affect the participants' quality of life. The symptoms negatively affected the participants' psychological wellbeing as well as their ability to work and partake in daily functional activities. However, only $31 \%$ of the participants reported experiencing these pathological vestibular symptoms to medical professionals. Furthermore, the participants reported that the medical professionals stated that the symptoms could be a side effect of the medication, and were often prescribed medication for their symptoms; however, none of these patients were referred for any sort of vestibular assessment and/or rehabilitation.

Internationally, several studies have suggested that there is a relationship between HIV/AIDS and the vestibular system. $.10,12,19$ In South Africa, the correlation between HIV/AIDS and the vestibular system is a fairly new area of research focus; nonetheless, the studies that have been conducted have also suggested a positive correlation. ${ }^{3,4,8}$ Findings from the current study, which examined vestibular symptoms in a group of adults with HIV/AIDS attending a HIV/AIDS clinic in a government hospital in Johannesburg, suggest that there is in fact vestibular abnormalities do occur in the HIV/AIDS population.

Results from the current study need to be considered in relation to methodological weaknesses identified in the project's research design and analysis. These include the small sample size, precluding use of inferential statistical calculations. Generalising findings to the larger population is limited. Furthermore, the participant selection criteria were broad. This could be viewed as a limitation to the study. In order to identify confounding pathologies or factors other than HIV/AIDS that could have been the cause of possible vestibular symptoms, comprehensive documentation of the patients' medical histories and medications was compiled. This information was then used to ensure that an accurate analysis of the data was executed; and, allowed the researcher to identify relationships between varying patient factors.

Despite these acknowledged limitations, some important implications were identified. Besides the implications for future research that include replication of the current study in larger sample sizes, with inclusion of objective vestibular function 
measures, current findings also raised implications for clinical assessment and management of adults with HIV/AIDS, as well as those for education of multidisciplinary team members on the importance of assessment and management of vestibular function in this population. It is of vital importance that further research be conducted in the area of the vestibular manifestation in patients with HIV/AIDS so that medical professionals may become more aware of the incidence of vestibular disorders and gain an understanding of how it can affect the patient's quality of life. Understanding vestibular function in this population may also guide clinical assessment and management of adults with HIV/AIDS. Although HIV/AIDS is incurable, medical professionals have a duty to address the comorbid conditions to improve patients' overall wellbeing.

\section{Summary}

- Current published evidence is mainly from international studies where the presentation as well as treatment of HIV/ AIDS in adults may be different; and, therefore, present vestibular symptoms differently. The current study is from a developing country context which is considered the epicentre of HIV/AIDS, with significant challenges with regards to HIV testing as well as treatment.

- No studies could be found which looked at quality of life and vertigo in HIV/AIDS adults, which is an aspect focused on in the current study

- Published evidence has looked at prevalence of vertigo in HIV/AIDS, but there is paucity of evidence from studies that have included investigating the nature of the vestibular symptoms, as well as whether these co-occurred with audiological symptoms - the current study did

- The current study also extended its scope by establishing management option for vestibular symptoms that this population has undergone.

\section{Financial support}

The work was supported by the National Research Foundation (Thuthuka Grant) as part of the first author's larger research study.

Acknowledgements - We would like to acknowledge Dr Sello Mashamaite from Thembalethu Clinic at Helen Joseph Hospital for his assistance during the data collection phase of this study; along with staff at this site for their impressive record keeping which was crucial for the record review aspect of this study

\section{Conflict of interest - None}

\section{Ethical standards}

The authors assert that all procedures contributing to this work comply with the ethical standards of the relevant national and institutional guidelines on human experimentation (The University of the Witwatersrand Medical Ethics Committee) and with the Helsinki Declaration of 1975, as revised in 2008.

\section{References}

1. Shisana O, Rehle T, Simbayi L, et al. South African National HIV Prevalence, Incidence and Behaviour Survey, 2012. Launch ed. Cape Town: HSRC Press; 2014. Available from Human Science Research Council: $\quad$ http://www.hsrc.ac.za/uploads/pageContent/4565/ SABSSM\%20IV\%20LEO\%20final.pdf.

2. Holmes $S$, Padgham N. A review of the burden of vertigo. J Clin Nurs. 2010;20(1):2690-701. Available from EBSCO Host database.

3. Heinze B, Swanepoel D, Hofmeyer L. Systemic review of vestibular disorders related to human immunodeficiency virus and acquired immunodeficiency syndrome. J Laryngol Otol. 2011;10:1-10.
4. Khoza K. Auditory function in a group of adults infected with HIV/ AIDS in Gauteng, South Africa [Unpublished master's thesis]. Gauteng: University of the Witwatersrand; 2001.

5. Khoza K. An investigation and monitoring of the auditory status in a group of adults with AIDS receiving anti-retroviral and other therapies attending a provincial hospitalHIV/AIDSclinicin Johannesburg South Africa[Unpublished doctoral dissertation]. Gauteng: University of the Witwatersrand; 2007.

6. Harris T, Heinze B. Tuberculosis (TB), aminoglycoside and HIV-related hearing loss; 2013. Available from Open Access Guide to Audiology and Hearing Aids for Otolaryngologists: https://vula.uct.ac.za/ access/content/group/27b5cb1b-1b65-4280-9437-a9898ddd4c40/ Tuberculosis\%20_TB_,\%20HIV\%20and\%20aminoglycoside $\% 20$ related\%20hearing\%20loss\%20_ototoxicity_pdf.

7. Kevetter GA, Blumberg KR, Correia MJ. Hair cell and supporting cell density and distribution in the normal and regenerating posterior crista ampullaris of the pigeon. Int J Dev Neurosci 2000;18:855-867.

8. Heinze BM, Vinck BM, Hofmeyr LM, et al. Vestibular involvement in adults with HIV/AIDS. Auris Nasus Larynx. 2014;41(2):160-8. http://dx.doi.org/10.1016/j.anl.2013.08.003

9. Hart C, Cokely C, Schupbach J, et al. Neurotologic findings of a patient with acquired immune deficiency syndrome. Ear Hear. 1989;10:68-76 http://dx.doi.org/10.1097/00003446-198902000-00012

10. Teggi R, Giordano L, Pistorio V, et al. Vestibular function in HIV patients: preliminary report. Acta Otorhinolarynagol Ital. 2006;26:140-6.

11. Teggi R, Ceserani N, Luce F, et al. Otoneurological findings in human immunodeficiency virus positive patients. J Laryngol Otol 2008;122:1289-94. http://dx.doi.org/10.1017/S0022215107001624

12. Pappas D, Roland J, Lim J, et al. ultrastructural findings in in the vestibular end-organs of AIDS cases, 16. Am J Otol. 1995;140-5.

13. Matcher A. Otosyphillis: auditory and vestibular manefestations. Am Jails. 2008:22:61-5.

14. Van Dyk AC, Van Dyk PJ. HIV and AIDS education, care and counselling: A multidisciplinary approach. Cape Town: Pearson Education; 2012.

15. Rogers C, Petersen L. Aminoglycoside-induced balance deficits:a review of vestibulotoxicity. S Afr Fam Pract. 2011;53(5):419-24. http://dx.doi.org/10.1080/20786204.2011.10874126

16. Vasquez R, Mattucci K. A proposed protocol for monitoring ototoxicity in patients who take cochleo- or vestibulotoxic drugs. Ear Nose Throat J. 2003;82(3):181-4.

17. Schacht J. Pharmacology and ototoxicity for audiologists. In: Campbell K, editor. Aminoglycoside antibiotics. New York, NY: Thomson/Delmar Learning; 2007. p. 163-176.

18. Cohen HS, Cox C, Springer G, et al. Prevalence of abnormalities in vestibular function and balance among HIV-seropositive and HIVseronegative women and men. In: Sluis-Cremer N, editor. PLoS ONE. 2012;7(5): e38419. doi:10.1371/journal.pone.0038419.

19. Palacios GC, Montalvo MS, Fraire MI, et al. Audiologic and vestibular findings in a sample of human immunodeficiency virus type1-infected Mexican children under highly active antiretroviral therapy. Int J Pediatr Otorhinolaryngol. 2008;72(11):1671-81. http://dx.doi.org/10.1016/j.ijporl.2008.08.002

20. Selimoglu E. Aminoglycoside-induced ototoxicity. Curr Pharm Des. 2007;13(1):119-26. http://dx.doi.org/10.2174/138161207779313731

21. Baloh R. Vertigo in older people. Curr Treat Opt Neurol. 2000;2:81-9. http://dx.doi.org/10.1007/s1 1940-000-0026-x

22. Tucci DL. Dizziness and vertigo; 2013, January. Available from Merck Manuals Online Medical Library: http://www.merckmanuals. com/home/ear_nose_and_throat_disorders/symptoms_of_ear_ disorders/dizziness_and_vertigo.html?qt=vertigo\&alt=sh.

23. Zingler V, Cnyrim C, Jahn K. Causative factors and epidemiology of bilateralvestibulopathyin255 patients.AnnNeurol.2007;61(6):524-32. http://dx.doi.org/10.1002/(ISSN)1531-8249

24. Irwin D, Pannbacker M, Norman J. Clinical research methods in speech-language pathology and audiology. Oxfordshire: Plural Publishing; 2014.

25. Polit DF, Beck CT. Nursing research: principles and methods. Philadelphia, PA: Lippincott Williams \& Wilkins; 2010.

26. Black K. Business statistics: contemporary decision making. Hoboken (NJ): Wiley; 2012

27. Mathews SS, Albert RR, Job A. Audio-vestibular function in human immunodeficiency virus infected patients in India. Indian J Sexual Transm Dis AIDS. 2012;33(2):98-101. http://dx.doi.org/10.4103/0253-7184.102115 
28. Desmond $\mathrm{AL}$, editor. Vestibular function: clinical and practice management. 2nd ed.. New York, NY: Thieme Medical; 2011.

29. Jacobson G, Newman C. The development of the dizziness handicap inventory. Arch Otolaryngol Head Neck Surg. 1990;116:424-7. http://dx.doi.org/10.1001/archotol.1990.01870040046011

30. Phellas C, Bloch A, Seale C. Structured methods: interviews, questionnaires and observation. In: Seale $C$, editor. Researching society and culture. London: Sage; 2012. p. 182-202.

31. Kranzer K, Lawn SD, Johnson LF, et al. Community viral load and CD4 count distribution among people living with HIV in a South African township. J Acquired Immune Defi. 2013;63(4):498-505. http://dx.doi.org/10.1097/QAl.0b013e318293ae48

32. Furman JM, Cass SP, Whitney SL. Vestibular disorders: a case-study approach to diagnosis and treatment. New York, NY: Oxford; 2010.

33. Schwaber MK. Vestibular disorders. In: Hughes GB, Myles L, editors. Clinical otology. New York (NY): Theime; 2011. p. 230-54.

34. Khoza-Shangase K. Pharmaco-audiology vigilance and highly active antiretroviral therapy (HAART) in South Africa: ototoxicity monitoring pursued. J AIDS Clin Res Sex Transm Dis. 2014;1:001.

35. Bronstein A. Oxford textbook of vertigo and imbalance. London: Oxford University Press; 2013. http://dx.doi.org/10.1093/ med/9780199608997.001.0001

36. Eagger S, Luxon LM, Davies RA, et al. Psychiatric morbidity in patients with peripheral vestibular disorder: a clinical and neuro-otological study. J Neurol Neurosurg Psychiatry. 1992;55(5):383-7.
37. Labuguen RH. Initial evaluation of vertigo. Am Fam Physician. 2006;73(2):244-51.

38. Bhattacharyya N, Baugh R, Orvidas L, et al. Clinical practice guideline: benign paroxysma positional vertigo. Otolaryngol Head Neck Surg. 2008;139(5):S47-S81.http://dx.doi.org/10.1016/j.otohns.2008.08.022

39. Furman JM, Jacob RG. A clinical taxonomy of dizziness and anxiety in the otoneurological setting. J Anxiety Disord. 2001;15(1-2):9-26. http://dx.doi.org/10.1016/S0887-6185(00)00040-2

40. Simbayi LC, Kalichman S, Strebel A, et al. Internalized stigma, discrimination, and depression among men and women living with HIV/AIDS in Cape Town, South Africa. Soc Sci Med. 2007;64(9):1823-31.

41. Yardley L, Putman J. Quantitative analysis of factors contributing to handicap and distress in vertiginous patients: a questionnaire study. Clin Otolaryngol. 1992;17:231-6. http://dx.doi.org/10.1111/ coa.1992.17.issue-3

42. Davis C, Morgan M. Finding meaning, perceiving growth and acceptance of tinnitus. Rehabil. Psychol. 2008;53:128-38. http://dx.doi.org/10.1037/0090-5550.53.2.128

43. Hosegood V, Preston-Whyte E, Busza J, et al. Revealing the full extent of households' experiences of HIV and AIDS in rural South Africa. Soc Sci Med. 2007;65(6):1249-59.

44. Rodgers C. A reveiw of childhood vestibular disorders. S Afr Fam Pract. 2014;52(6):514-7.

Received: 11-04-2016 Accepted: 22-07-2016

\section{Appendix A.}

(Khoza-Shangase \& Van Rie, 2016)

\begin{tabular}{l|l|l|} 
Case History \\
\hline Patient file no: & & \\
\hline Patient number: & & \\
\hline Age: & & \\
\hline Gender: & FM & \\
\hline
\end{tabular}

\section{Medical status:}

\begin{tabular}{|l|c|}
\hline HEALTH AT PRESENT? & \\
\hline Good & $>500$ \\
\hline Fair & $200-499$ \\
\hline Bad/poor & $<200$ \\
\hline
\end{tabular}

\section{Vestibular symptoms}

Do you ever feel dizzy? (As if the room is spinning around you or you are spinning around the room.)

\begin{tabular}{l|l|c|l|l|} 
& \multicolumn{1}{|c|}{ Yes } & No & & Yes \\
\hline Dizziness & $\checkmark$ & $\mathbf{X}$ & & Vertigo \\
\hline \\
"I sometimes feel weak and unsteady and feel like I want to faint. I have to \\
sit down for a little bit before I can carry on"
\end{tabular}

\section{Symptoms:}

Tick which symptoms apply to you in the boxes below.

\begin{tabular}{|l|l|l|l|l|}
\hline Symptom & $\checkmark$ & Symptom & $\checkmark$ & Symptom \\
\hline Dizziness & Spinning & Fatigue \\
\hline Lightheaded & Headache & Other: \\
\hline Falling & Confused & \\
\hline Unsteadiness & Double vision & \\
\hline Rocking/tilting & Nausea/vomiting & \\
\hline Fainting & Visual changes & \\
\hline
\end{tabular}


When did you first start feeling this way?

Was it associated with a specific event? YES NO

When did you start feeling symptoms?: Suddenly-overnight Slowly other

The symptoms are..... always there Come and go

If it comes and goes:

It occurs every (\# of): ___ hours/___ days/___weeks___/months

a) It lasts for: ___ seconds/__ minutes/__ hours/__ days

Have you ever been to a doctor to check the dizziness and for therapy? YES NO

Who?

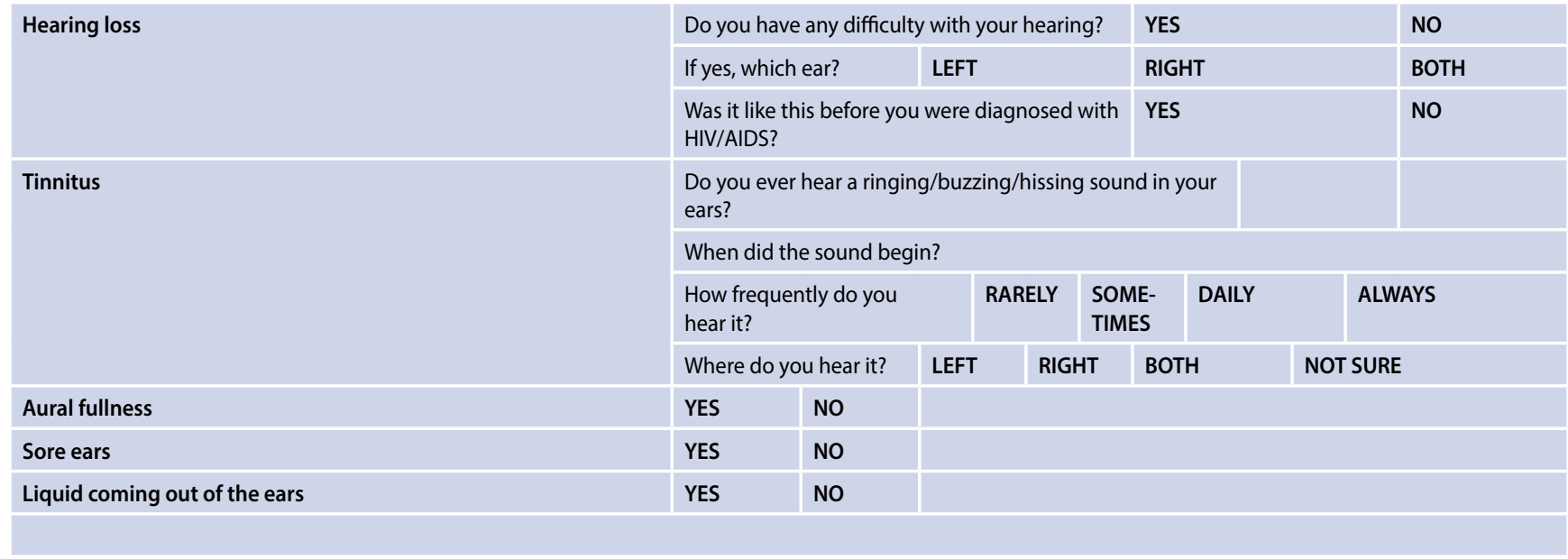

\section{IDENTIFYING COMORBID PATHOLOGIES AND MEDICATION}

Have you ever suffered from the following medical problems?

\begin{tabular}{|l|l|l|l|l|}
\hline MEDICAL PROBLEM & $\checkmark$ & MEDICAL PROBLEM & $\checkmark$ & MEDICAL PROBLEM \\
\hline Trauma to the head & & Concussion & & Parkinson's disease \\
\hline TB & & Multiple sclerosis & Stroke \\
\hline Cancer & Glaucoma & Diabetes \\
\hline Syphilis & Neuropathy & Ataxia \\
\hline High/low BP & Tumour & Seizures \\
\hline Migraine headaches & Anxiety/panic attacks & Other: \\
\hline Meniere's disease & Cervical spine Arthritis & \\
\hline
\end{tabular}

\section{Current prescribed medication:}

\begin{tabular}{|l|l|l|}
\hline MEDICATION NAME & REASON \\
\hline 1. & \\
\hline 2. & \\
\hline 3. & \\
\hline 4. & \\
\hline 5. & \\
\hline 6. & \\
\hline
\end{tabular}




\section{FILE REVIEW}

\section{EFFECT ON QUALITY OF LIFE AND ACTIVITIES OF DAILY LIVING}

How does the dizziness affect your day-to-day life? (Probe: ability to do certain activities/ do your job/ walk and travel to places/ household chores etc.).

\begin{tabular}{|l|l|}
\hline Does it affect your ability to work? & Is it more difficult to do housework? \\
\hline Is it difficult to use transport? & Is it difficult for you to walk? \\
\hline Are you scared to go out alone? (In case of falling/vomiting etc.) & Do you do less activities now than you used to? (Because of the dizziness etc.) \\
\hline Does your dizziness etc. make you feel sad? & \\
\hline NOTES: & \\
\hline
\end{tabular}

How does it make you feel when you are around other people?

\begin{tabular}{|l|l|l|}
\hline & 1. Embarrassed & 2. Frustrated \\
\hline NOTES: & & 4. Irritable \\
\hline
\end{tabular}

Any additional information you feel the researcher should know? 